\title{
1 A People-Centric Sensing Approach to Detecting Sidewalk Defects
}

2

3 Hyunsoo Kim, ${ }^{1}$ Changbum R. Ahn, ${ }^{2}$ Kanghyeok Yang ${ }^{3}$

4

6 Hall, Lincoln, NE 68588; e-mail: cahn2@unl.edu (corresponding author) Hall, Lincoln, NE 68588; e-mail: kyang12@ @uskers.unl.edu

2 Assistant Professor, Construction Engineering and Management, Charles Durham School of Architectural Engineering and Construction, University of Nebraska-Lincoln, W113 Nebraska

3 Ph.D Student, Construction Engineering and Management, Charles Durham School of Architectural Engineering and Construction, University of Nebraska-Lincoln, W113 Nebraska 


\section{Abstract}

A defective sidewalk inhibits the walkability of a street and may also cause safety accidents (slips, trips, and falls) for pedestrians. When a pedestrian walks along a sidewalk, his/her behaviors may vary according to the condition of the sidewalk-e.g., whether the surface is normal, holed, cracked, tilted, or sloped. As a result, the pedestrian's stability may also change according to the built environment's conditions. Accordingly, this paper examines the feasibility of using pedestrians' physical behaviors to detect defects in a sidewalk. Pedestrians' physical responses and paths over a sidewalk are collected using an inertial measurement unit (IMU) sensor and a global positioning system (GPS). Then, after aggregating the pedestrians' bodily responses and locations, the irregularity of multiple pedestrians' responses are calculated in relation to their locations. The locations that show irregularities in the pedestrian-response patterns present a high correlation with the existence of a defect. The results of this study will help improve the continuous diagnosis of defects in sidewalks, thereby enhancing these built environment systems' serviceability. 


\section{Introduction}

Built environments, including civil infrastructure and buildings, are designed to provide specific services to users [1]. Maintaining a sufficient service level for users is thus critical for achieving each built environment's designed objectives [2-4]. Of the numerous types of built environments, the sidewalk is one of the most influential infrastructures for humans since it is an integral part of sustainable transportation, and supports pedestrian travel as well as healthy physical activity [5]. What is more, the quality of sidewalks is a significant indicator of the perceived safety and quality of the pedestrian environment [6]. cost per defective sidewalk claim was over fifteen thousand dollars. Besides the cost of settling these claims, the detection of defective sidewalk is important for enhancing the safety of pedestrians, including disabled and elderly persons. According to the Americans with Disabilities Act of 1990 (ADA), pedestrian infrastructure is legally considered part of the "public right of way," and governmental agencies can be liable for injuries resulting from inadequate maintenance of infrastructure, including sidewalks. For these reasons, addressing the problems caused by defects in sidewalks is valuable not only for pedestrians, who deserve access to safe sidewalks, but also for those who are legally responsible for defects, such as governments or owners. Governmental agencies in the United States have thus taken various approaches to addressing such issues, including performing periodic inspections using experts [7], 10] and transferring liability of sidewalk maintenance from the city to property owners. Nonetheless, claims related to defective sidewalks continue to grow in terms of both 
sidewalk defects in a continuous and automated fashion.

To this end, this paper investigates the feasibility of harnessing pedestrians' bodily responses to their environment as a means of detecting defects in a sidewalk. According to several studies [10-13], humans physically respond to the changes in their physical environment. For example, when a pedestrian walks along a sidewalk that includes a defect, his balance or gait stability changes at the moment of stepping on or over the defect. Therefore, human responses to the surrounding environment may offer information that lets us estimate the condition of the environment. To examine the feasibility of such a peoplecentric sensing approach, we collected data from inertial measurement unit (IMU) sensors to measure pedestrians' bodily responses and data from global positioning systems (GPS) to locate pedestrians; these data are used to analyze pedestrians' bodily responses to their location.

The paper is organized as follows: first, we review current practices and related techniques. Next, we introduce challenges in detecting sidewalk defects using pedestrians' bodily responses, and then propose a hypothesis for the relationship between pedestrians' bodily responses and defect existence. To examine the suggested hypothesis, an outdoor experiment is performed on an actual sidewalk. The discovered relationship between the pedestrians' bodily responses and the defect's existence is expected to provide a basis for developing a proactive monitoring system that empowers the stakeholders who are responsible for injuries caused by defective sidewalks to be able to continuously monitor and maintain the quality and the function of their sidewalks.

\section{Background}

\subsection{Current Efforts for Defective Sidewalk Detection}

Although there are many people who use vehicles as a transportation method, walking is 
still the best method of moving short distances, making sidewalks an integral component of human movement. According to [14], there are several objectives for sidewalks, including linking buildings, setting up facilities, and providing an emergency escape route. To fulfill these objectives, sidewalk defects should be well managed. A management process for sidewalks includes several steps, among which the detection of defects is the first step. A common practice for detecting a sidewalk defect is a user survey that focuses on a user's evaluation/satisfaction with a particular facility [15]. A user reports detected defects to a governmental agency, and then the agency checks the status of the defect and manages it. However, outcomes of surveys and reports are often affected by respondents' temporary emotions, recent experiences, and familiarity with the facility. Surveys are also not efficient in terms of time and cost, nor are they very effective in providing detailed analysis of defect existence, which ultimately causes a decrease in sidewalk quality [16]. conditions) and usage patterns (e.g., user traffic). For example, regulations for pedestrian sidewalks in Iowa define a sloped sidewalk of more than $2 "$ in an $8^{\prime}-10^{\prime}$ length as a defective 
(e.g., agile or disabled), user traffic, and weather (e.g., snowy, icy, etc.). Furthermore, the

Table 1. Defective-Sidewalk Regulations

\begin{tabular}{|c|c|c|c|}
\hline Description of Defective-Sidewalk Standard & $\begin{array}{c}\text { IA } \\
\text { (Dubuque) }\end{array}$ & $\begin{array}{c}\mathrm{NE} \\
\text { (Omaha) } \\
\end{array}$ & $\begin{array}{c}\text { CA } \\
(\text { San Francisco) }\end{array}$ \\
\hline $\begin{array}{c}\text { Vertical or horizontal separations equal to or greater } \\
\text { than a specific range. }\end{array}$ & $3 / 4 "$ & $1 "$ & $1 / 2 "$ \\
\hline $\begin{array}{c}\text { Holes or depressions equal to or greater than a specific } \\
\text { range. }\end{array}$ & 3/4" & $3 / 8 "$ & $1 / 2 "$ \\
\hline $\begin{array}{c}\text { Spalling over fifty }(50 \%) \text { percent of a single square } \\
\text { with a depression equal to or greater than a specific } \\
\text { range. }\end{array}$ & 3/4" & $3 / 8 "$ & $1 / 2 "$ \\
\hline $\begin{array}{c}\text { A single square cracked into more than three (3) pieces } \\
\text { OR sections distorted equal to or greater than specific } \\
\text { range. }\end{array}$ & 3/4" & $1 / 2 "$ & $1 / 2 "$ \\
\hline $\begin{array}{l}\text { Sidewalk is raised (or depressed) more than a specific } \\
\text { range from the normal grade of the sidewalk. }\end{array}$ & $\begin{array}{l}2^{\prime \prime} \text { in an } 8^{\prime}- \\
10^{\prime} \text { length }\end{array}$ & $\begin{array}{l}2 " \text { in an } 8^{\prime} \\
\text { length }\end{array}$ & $\begin{array}{l}1 / 2 " \text { per foot of } \\
\text { transition }\end{array}$ \\
\hline $\begin{array}{l}\text { Water stop box is raised or lowered equal to or greater } \\
\text { than a specific range and/or lid is cracked or missing. }\end{array}$ & $3 / 4 "$ & None* & None* \\
\hline
\end{tabular}

*No specific regulation

\subsection{People Centric Sensing}

Considering the fact that sidewalks are meant for pedestrian use, the involvement of actual users is very important when evaluating the quality, function, and defects of sidewalks. Recent efforts have sought to transform human users into sensors-a concept called "peoplecentric sensing." This approach mainly focuses on collecting targeted information about users' daily patterns and interactions [24, 25]. Although the sensory coverage of spaces [21], events [19], health [22,23], and social interactions [24-26] is beneficial for people or citizens [20], people-centric sensing is an immature research area for detecting built environment system defects because most current people-centric sensory research has focused on humans or the 
interaction between humans, not on the interaction between users' responses and external systems. One representative method that estimates external system conditions using user responses is pothole detection on a motor vehicle road. This method detects potholes using a vehicle response, such as the abnormal vibrations observed when driving over a pothole [27]. Additionally, there are other, similar studies utilizing bicycles [28] and wheelchairs [29, 30]. Although these prior works provide evidence of the viability of detecting unstable conditions [27, 31-33] from wheel-based equipment, to the best of the authors' knowledge, no one has collective responses could thereby be used to identify defects in sidewalks. 
However, the magnitude of variability in pedestrians' responses to a defect in a sidewalk

is a technical hurdle. The magnitude of a response to a defect during walking is generally smaller than other activities the pedestrian may perform—such as running, swinging an arm, slipping, falling, etc. [34]. Prior work has employed diverse techniques for detecting these assorted larger-magnitude bodily responses. For example, researchers have applied vision techniques to analyze human body motions to identify the risk of injury [35-37]. While such research has numerous strengths, distinguishing the subtle movements of a pedestrian using visual information is difficult. Recently, diverse research projects using sensory techniques have been performed to analyze such bodily responses as muscular engagement [38], fatigue [39], and gait stability [38, 39]. Problematically, to obtain the information required for these projects, devices must be attached to the body, which in turn can affect human bodily response. Additionally, pedestrians may not be familiar with or hospitable to these devices since they can inhibit the pedestrians' daily life.

Therefore, there are two requirements for a data-collection method of the proposed people-centric sensing approach: 1) a method must capture subtle body responses, and 2) a sensory device should not inhibit humans' daily life. An IMU sensor is one option for capturing subtle body responses that satisfies the first requirement. In clinical domains, IMUs have been used to measure human body stability [42]. Several researchers have proposed the applicability of IMUs to measure subtle response changes during walking [43,44]. Among devices capable of mounting an IMU to a subject, a smartphone works well and can satisfy the second requirement as well as the first. These devices usually already include built-in IMU sensors, and many pedestrians keep a smartphone on their body. In addition, a smartphone has additional advantages in its ability to not only detect a defect using pedestrians' bodily responses, but also to locate detected defects and transfer whole 
information (e.g., existence and location) to help develop a proactive sidewalk management process.

In summary, pedestrians' bodily responses may include crucial information that can identify the existence of defects. Pedestrians often keep a smartphone on their person, allowing researchers to observe subtle body responses in daily life. Consequently, we hypothesize that changes in pedestrians' bodily responses collected from their smartphones are highly correlated with defects in a sidewalk. We test this hypothesis by analyzing experimental results performed on an actual sidewalk.

\section{Experiment Design and Method}

\subsection{Experiment Design}

Outdoor experiments were performed on a sidewalk. Seventeen subjects-nine males and eight females—-were recruited and asked to walk on a sidewalk at a comfortable velocity with a smartphone in their right front pants pocket. None of the subjects had any clinical problems. Table 2 summarizes their physical information.

Table 2. Physical Subject Information

\begin{tabular}{llll}
\hline Statistical Parameters & Height (ft.) & Weight (lb.) & Age (years) \\
\hline Mean & 5.76 & 153.24 & 26.4 \\
Median & 5.8 & 159 & 27 \\
Standard deviation & 0.33 & 25.9 & 3.17 \\
Minimum value & 5.2 & 110 & 22 \\
Maximum value & 6.4 & 187 & 33 \\
\hline
\end{tabular}

Figure 1 illustrates an overview of the experiment and its location. The experiment was performed in front of a city street in Lincoln, NE, in the US. This location would be considered a "light traffic" street in terms of the number of pedestrians regularly accessing it, 
and the experiment was performed when subjects' walking was not interfered by the traffic of other pedestrians. During the experiment, each subject was asked to carry a smartphone and to use the sidewalk to walk from the starting point to the ending point in Figure 1-a ten times. All subjects were asked to wear tight pants (preferably jeans) to minimize any movement within their pockets, and running shoes to reduce any bias caused by a less stable shoe. their locations were recorded using GPS.
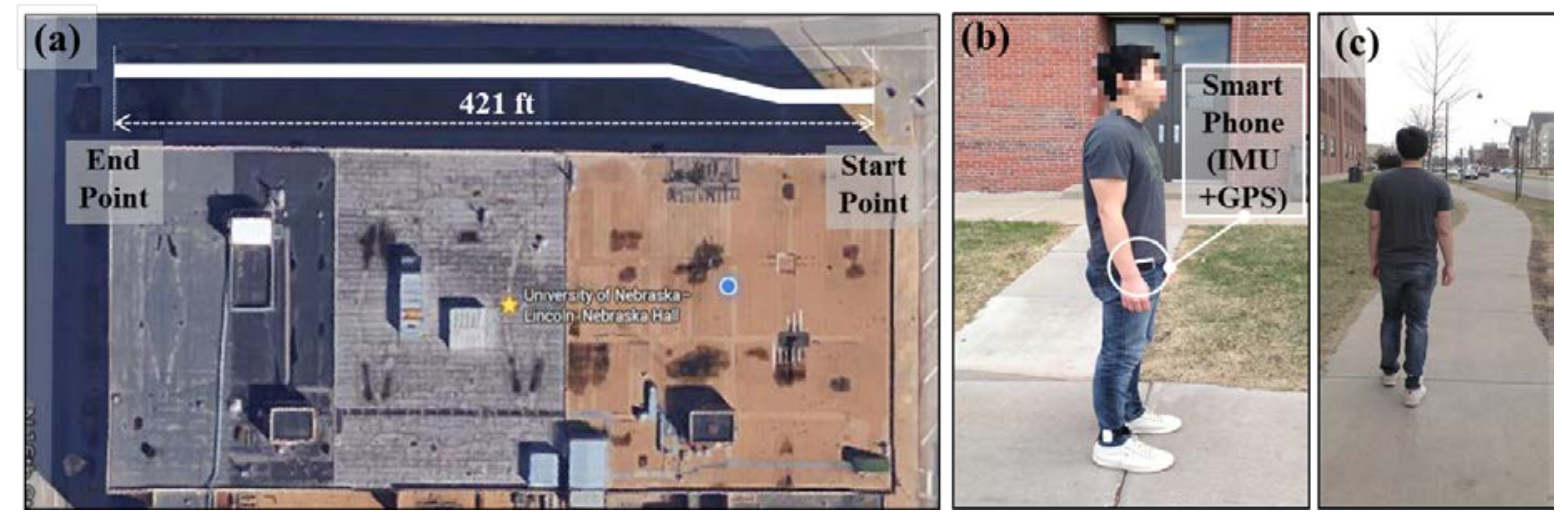

208

Figure 1. Experiment Overviews: (a) Experiment Location; (b) Device and Subject; (c)

Experiment Location and Subject

Table 3 provides visual evidence of the terrain at the experiment site (sidewalk). There were 16 defects on the sidewalk, including 13 holes that were greater than 3/4", three cracked surfaces, and one vertical separation surface. The pedestrians' bodily responses were then compared to the existence of defects.

Table 3. Sidewalk Defects at the Experiment Site

\begin{tabular}{llll}
\hline $\begin{array}{l}\text { Defect } \\
\text { Location Description } \\
\text { (ft.) }\end{array}$ & Figure & $\begin{array}{l}\text { Defect } \\
\text { Location Description } \\
\text { (ft.) }\end{array}$ & Figure \\
\hline
\end{tabular}




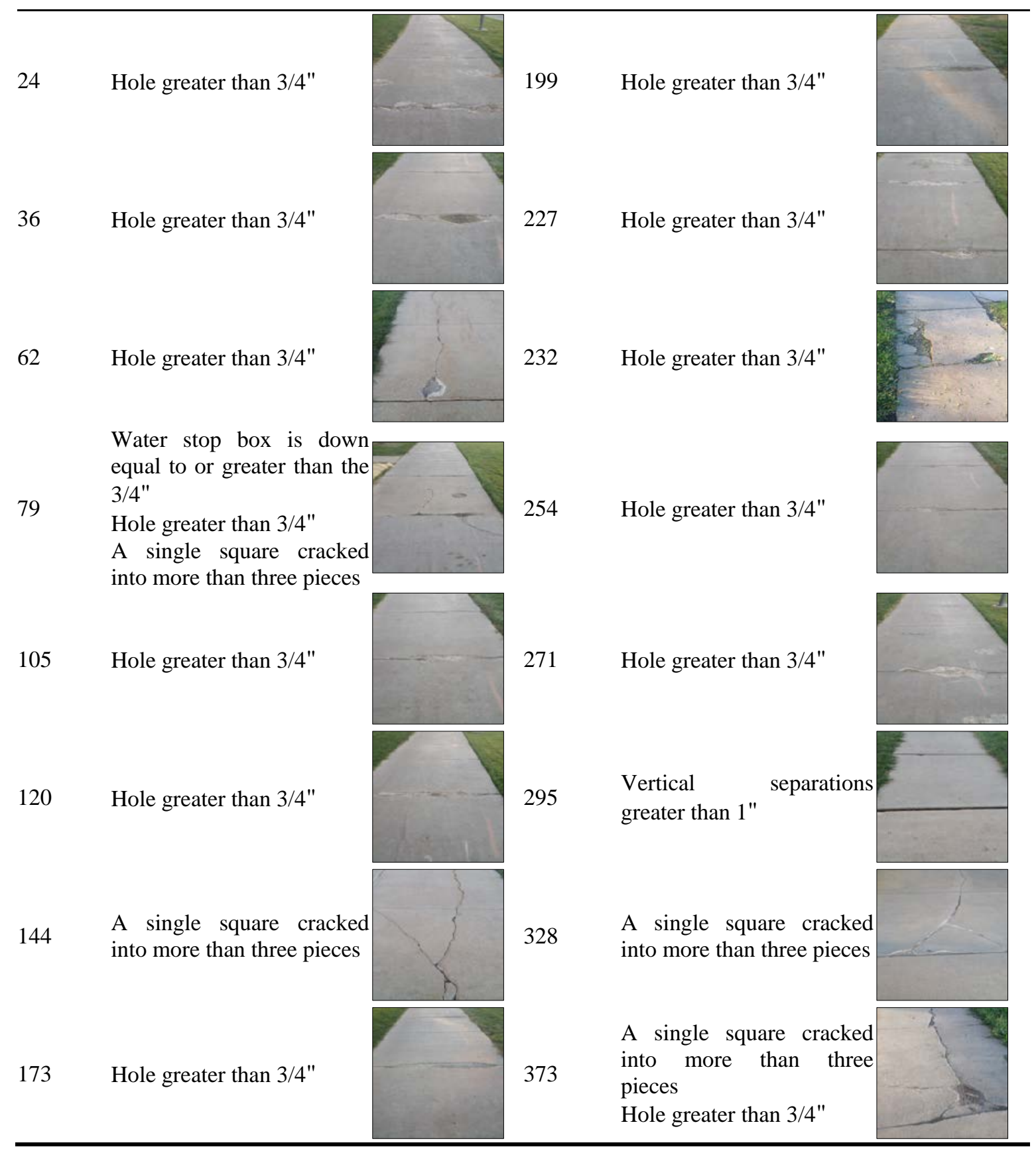

\subsection{Data Analysis Method}

To collect subtle body responses, this study uses a signal vector magnitude (SVM) that is calculated based on three axes of acceleration. An SVM measures the extent to which a body moves by averaging the acceleration's signal power [45]. In several previous studies [43, 44], an SVM was used to measure the severity of response. However, in these studies, the accelerations were measured according to time, not location, so here there is a need to 
convert an SVM calculated by time into an SVM by location. To achieve this conversion, we calculate an average (mean value) of observed SVM values in a specific location (the location window size is defined as one foot)._Using Equation 1, the $\mathrm{SVM}_{i j}$ and SVM values of $j$ th subject on $i$ th segment (each segment is one foot) are calculated as the root of the square sums of three axes' acceleration signals.

$$
S V M_{i j}=\left[\sum_{k=1}^{n} \sqrt{x_{k}^{2}+y_{k}^{2}+z_{k}^{2}}\right] / n,
$$

where $n$ is the total number of IMU measurements of $j$ th subject on $i$ th segment, $x_{k}$ is $k$ th acceleration of anterior-posterior axis, $y_{k}$ is $k$ th acceleration of horizontal axis, and $z_{k}$ is $k$ th acceleration of vertical axis.

Although an SVM has the potential to detect a subtle bodily response [47], an SVM range varies by subject because each subject's physical characteristics are unique. This difference may make it difficult to integrate multiple subjects' bodily responses using an SVM. The relative ratio to the average has been used to deal with this difference [46-48]. To compare how a bodily response in a particular location differs from an average of each subject's SVM, a relative $\mathrm{SVM}\left(\mathrm{RSVM}_{i j}\right)$ is suggested in this study. $\mathrm{RSVM}_{i j}$ values compare how an individual's body's movement in a specific location differs from the individual's average movement. An $\mathrm{RSVM}_{i j}$ is defined as the ratio of the SVM by location to the average SVM of each subject and can be calculated as Equation 2.

$$
R S V M_{i j}=\frac{S V M_{i j}}{\left[\sum_{i=1}^{N} S V M_{i j}\right] / N},
$$


Figure 2 illustrates the raw data from the experiment, the scatter plot of RSVM values of all subjects, and the dispersion of three locations. Collected raw data are converted into RSVM values by following Equation (2). In figure 2-a, two subjects' experimental data are shown. It is difficult to detect the defect existence and location with this data due to the individualized nature of the data. These two subjects have different responses even on the same defect. However, the collective data from multiple subjects can be more meaningful in detecting a defect. In Figure 2-b, most data are within a range from 0.5 to 1.5 (approximately 90\%). However, several locations have higher RSVM values, such as at section (1) in Figure 2-b. It can be assumed therefore that there is a response change in these locations. If viewed in detail, we may find an element that can intensify a pedestrian's responses. However, although these higher values can indicate a defect's existence, a higher value itself does not guarantee a defect's existence. In the case of (2) in Figure 2-b, though the location includes vertical separation, no higher RSVM value is found. The brief data overview confirms that simply using the response magnitude cannot guarantee a reliable detection of sidewalk defects. Figure 2-c shows the RSVM histograms of three typical locations. Investigating the data at specific locations provides several interesting points. The first (a hole defect) and second (a vertical separation defect) histograms in Figure 2-c show a negatively and a positively skewed distribution, respectively. Comparatively, responses in a location where there are no defects (e.g., Figure 2-c) usually follow a normal distribution. This means that unlike with response magnitude, the normality of responses at a specific location can be used as an indicator for detecting the existence of a defect. 


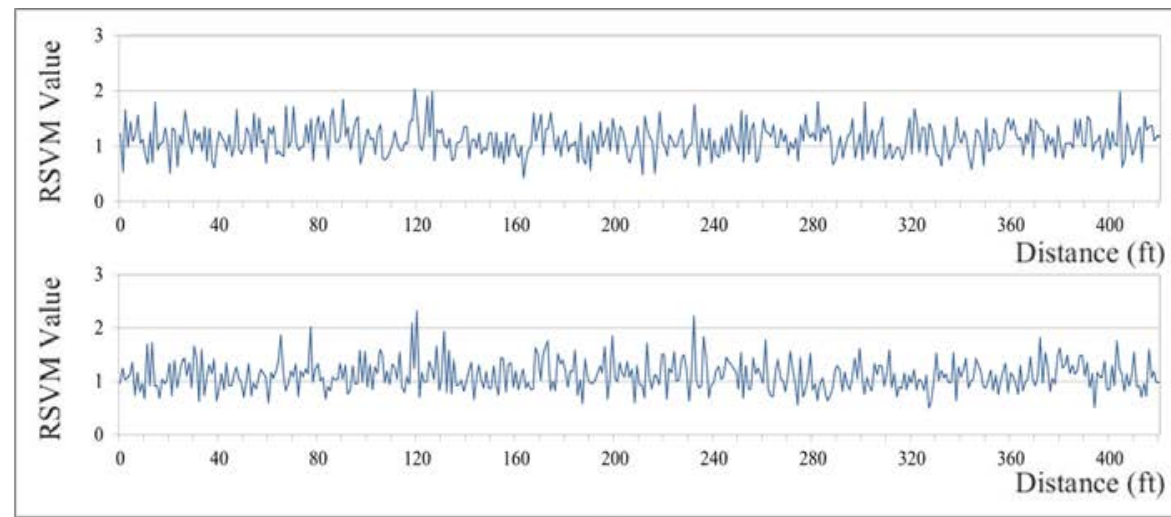

(a)

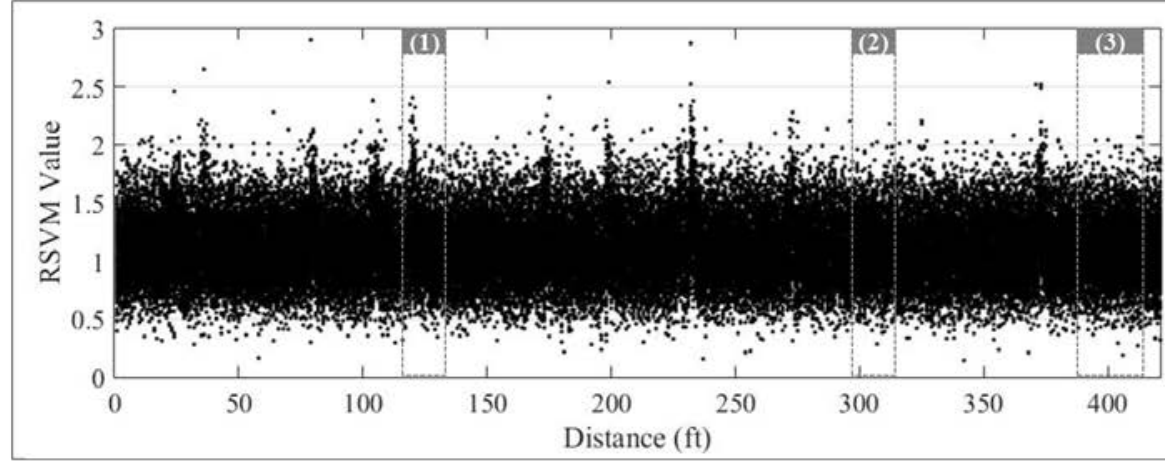

(b)
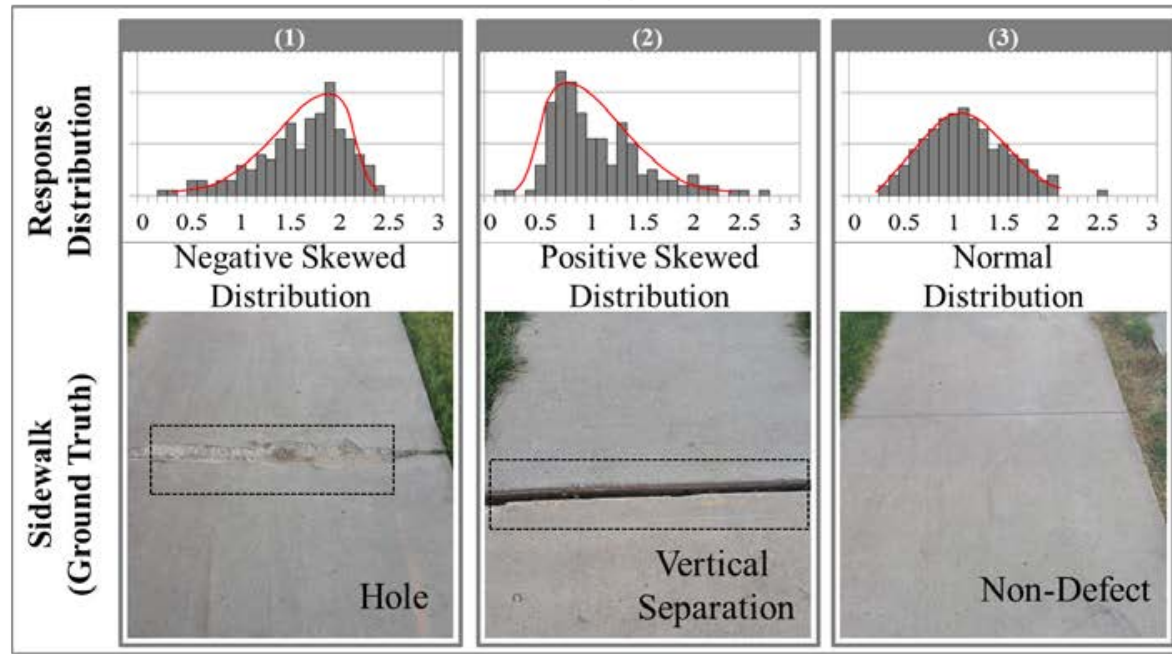

(c)

Figure 2. Data Overview: (a) Example of Two Subjects' RSVM values; (b) Scattered

Data Plot of Whole Subjects; (c) Histograms of RSVM Values in Three Cases (Hole, Vertical

Separation, and Non-Defect Surface) and Images of Corresponding Terrain. 

location, which is used to analyze response severity; and 2) the Shapiro-Wilk (W) statistic of following equation:

$$
W=\left(\sum_{i=1}^{n} a_{i} x_{(i)}\right)^{2} / \sum_{i=1}^{n}\left(x_{i}-\bar{x}\right)^{2},
$$

where $x_{i}$ is the $i_{t h}$ order statistic; $\bar{x}$ is the sample mean $\left(\bar{x}=\left(x_{1}+x_{2}+\cdots+x_{n}\right) / n\right) ; a_{i}$ is the set of constants are given by $\left(a_{1}, \cdots, a_{n}\right)=m^{T} V^{-1} /\left(m^{T} V^{-1} V^{-1} m\right)^{1 / 2} ; m$ is the expected values of the order statistic of independent and identically distributed random variables sampled from the standard normal distribution and given by $m=\left(m_{1}, \cdots m_{n}\right)^{T}$; and $V$ is the covariance matrix of those order statistics.

\section{Results}

The results of the experiment are shown in Figure 3. Each result was calculated respectively based on the average of the RSVM values and the $W$ statistic of RSVM values collected from a total of 170 tests (17 subjects and 10 experiments from each subject). The 16 locations marked in grey indicate existing defects, as determined by existing defective sidewalk regulations. In several grey locations, the average RSVM values are much higher than those of non-defective sidewalks (see Figure 3-a). This indicates that pedestrians' bodily responses at those locations are highly affected as compared to non-defective sidewalk locations. There are 11 peak points at grey locations. However, several defects do not display 
$\mathrm{ft}$ (hole), $144 \mathrm{ft}$ (cracked into more than three pieces), $254 \mathrm{ft}$ (hole), $295 \mathrm{ft}$ (vertical separation), and $328 \mathrm{ft}$ (cracked into more than three pieces) do not manifest in the data in a way that would serve as crucial information for detecting a defect in sidewalks.

Figure 3-b illustrates the results of the $W$ statistic of RSVM by location. In non-defective sidewalks, the range of the $W$ statistic is from 0.92 to 0.99 . Such high $W$ statistics mean that pedestrians' collective responses in non-defective sidewalks follow a normal distribution with a very high probability. On the other hand, the distribution of pedestrians' responses is very disordered in defect locations. In some defect locations, $W$ statistics range from 0.78 to 0.88 . There are 14 peak points below 0.9 at grey locations. In particular, the defects located at 144 $\mathrm{ft}$ and $295 \mathrm{ft}$ can be detected by $W$ statistics, but cannot be detected by only using the average of RSVM values. The low normality of pedestrians' collective bodily responses are well matched to the defect existence except for defects located at $62 \mathrm{ft}$ and $328 \mathrm{ft}$. However, unlike the average of RSVMs, a low $W$ statistic was observed on a stretch of non-defective sidewalk 316 located between two identified defects, which were located very close together (between 227 $\mathrm{ft}$ and $232 \mathrm{ft})$. 


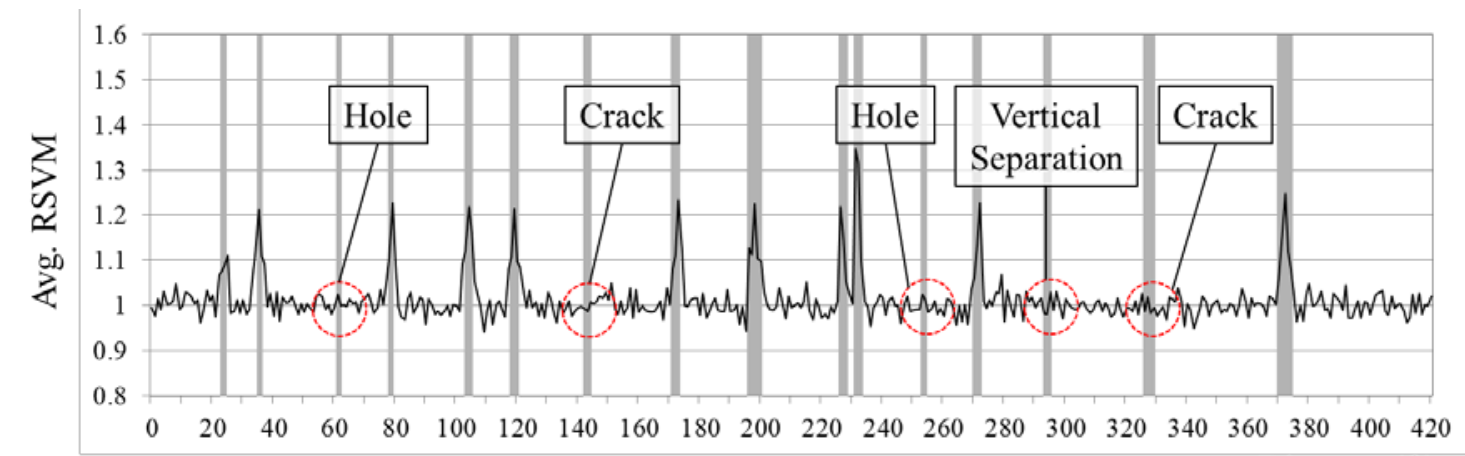

(a)

Distance (ft)

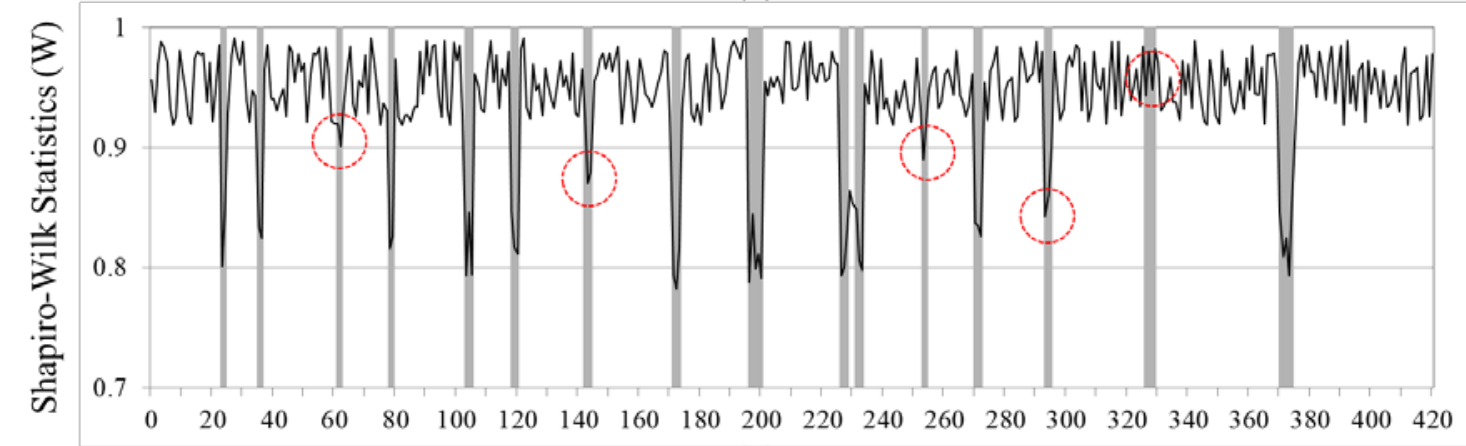

(b)

Distance (ft)

Figure 3. Calculation Results of Whole Subjects: (a) Average of RSVM Values; and (b)

Shapiro-Wilk Statistic $(W)$

The RSVM values by location are continuous variables, whereas the existence of defects can be represented as a binary variable (existence as 1 or nonexistence as 0 ). To analyze the relationship between a defect's existence and pedestrians' bodily responses in a statistical manner, this study used the point biserial correlation coefficient $\left(r_{p b}\right)$. (The point biserial correlation coefficient is used when one variable is dichotomous and the other is not.) The point biserial correlation coefficients between a defect's existence and pedestrians' responses are calculated by using the following equation.

$$
r_{p b}=\frac{\left(M_{1}-M_{0}\right) \sqrt{\left(n_{1} n_{0} / n^{2}\right)}}{\sqrt{\frac{1}{n} \sum_{i=1}^{n}\left(X_{i}-\bar{X}\right)^{2}}},
$$


where $M_{l}$ is the mean value on the continuous variable $X$ (the average of RSVM or the

$W$ statistic of RSVM) for all data points in group 1 (Defect Existence); $M_{0}$ is the mean value

of the continuous variable $X$ (the average of RSVMs or the $W$ statistic of RSVMs) for all data points in group 2 (Defect Nonexistence); $n_{1}$ is the number of data points in group $1 ; n_{0}$ is the number of data points in group 2; and $n$ is the total sample size.

Based on the point biserial correlation, the correlation between each metric and a defect's existence were compared. The coefficients of each metric are 0.65 (for the average of RSVM values) and -0.79 (for the $W$ statistic of RSVMs), respectively. According to previous research $[49,50]$, a correlation coefficient over 0.7 indicates a high degree of correlation. In the results, we find that the $W$ statistic (of pedestrians' collective bodily response) and defect existence are highly correlated. It can be thus concluded that the normality of pedestrians' collective responses shows a higher correlation with a defect's existence in sidewalks.

To estimate the location of defects in the sidewalk, $k$-means clustering was used to classify data into two groups based on nearest-centroid sorting. In this method, data are classified into a predetermined number of groups (clusters). Data (e.g., the subjects' bodily response data) observed within a certain location (a foot) is assigned to the cluster with the smallest distance between the data and the center of the cluster, or centroid [54]. Since the condition of a sidewalk can only be classified into either with a defect or without a defect, the value of $k$ (the number of clusters) is determined to be 2 . As can be seen in Figure 4, each location's data are classified into two groups: 1) locations determined to be "normal" conditions (true negative $(n=372)$ and false negative $(n=14))$; and 2) locations determined to have defects (true positive $(n=33)$ and false positive $(n=2))$. Based on this result, the accuracy is 0.962 , the precision is 0.943 , and the recall is 0.702 . 

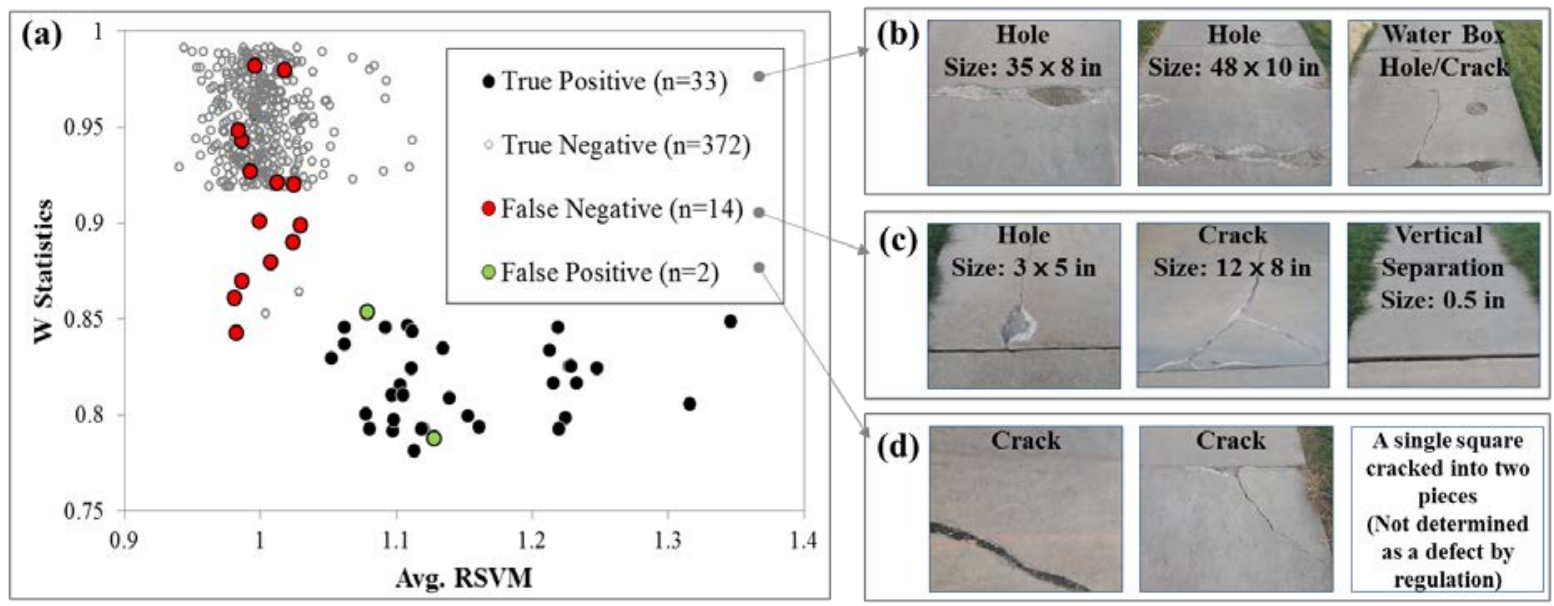

Figure 4. Clustering Results and Images of Corresponding Terrain: (a) $k$-Means Clustering

Results; (b) Examples of True Positive Points; (c) Examples of False Negative Points; and (d)

Examples of False Positive Points.

Although the high degree of accuracy, including precision and recall, may indicate that

the suggested clustering result is feasible for detecting and locating defects, it would be

valuable to conduct further investigation into the reasons why the false negative (falsely

estimated defective sidewalk) and false positive (falsely estimated normal sidewalk) points

appear. Comparing true negative points to true positive points and false negative points, true negative points generally show lower $W$ statistic values and higher average RSVM values than the false negative points. The reasons why several defects are determined to be false negative points can be as follows: First, even though defects determined to be false negatives fulfill defective sidewalk regulations, these defects may not affect pedestrians' bodily responses since the defects could be diminutive. For example, two holes which formed a defect cluster were identified as false negatives (see Figure 4-c); these holes had an average size of $3.5 "$ by 6", notably smaller than general holes (whose average size is $41.2 "$ by $9.6 "$ ). 
bodily responses. Second, it is possible that there are errors in the study. The vertical separation (see Figure 4-c) has an average RSVM value under 1.0 and a $W$ statistic value under 0.9. The range of values presented on the vertical separation is located between true negative points (cluster 1) and true positive points (cluster 2). This result may mean that the vertical separation does not cause enough magnitude or dispersed distribution to be identified as a defect.

Within our results, two locations were determined to be false positives. These two locations provide a great opportunity to consider the relationship between an actual defect and the sidewalk regulations. In the regulations, a sidewalk square cracked into more than three pieces is identified as a defect. However, a crack that divides a single square into just two pieces can also affect pedestrians' bodily responses. In Figure 4-d, cracks (false positives) caused pedestrians' bodily responses to disperse obviously in terms of low $W$ statistics. This finding may indicate that defective sidewalk regulations do not cover all defect types in actuality, and that there are some conditions not identified as defects by regulations which affect pedestrians' walking as much as do identified defects. It also indicates that regulations should be improved by taking into consideration the interaction between a defect and a pedestrian. Even though, the clustering results show acceptable accuracy, future studies are required to minimize the number of false positives and false negatives for enhancing the accurate detection of sidewalk defects.

\section{Discussions}

The previous section demonstrates that the $W$ statistic can be used to detect defects in sidewalks by utilizing pedestrians' collective bodily responses. This section will provide 
further discussion about 1) needs for collective sensing to detect defects in sidewalks; 2)

402

403

404

405

406

407

408

409

410

411

412

413

414

415

416

417

418

419

420

421

422 walking patterns for defective sidewalks; 3) the effect of pedestrian familiarity with particular sidewalks; 4) the possibility of people centric sensing to detect defects; and 5) limitations and future research.

\subsection{Needs for Collective Sensing}

In this paper, results are deduced based on the collective sensing approach, and we have shown that the normality of pedestrians' response distribution is highly correlated with defect existence. Response differences between subjects are the key for performing this analysis. If there is no response difference between subjects, we can estimate the location of a defect by using the magnitude of responses. However, each individual presents his or her bodily response differently from another. Figure 5 illustrates two subjects' data in order to examine the reason why individuals present different bodily responses from each other. Comparing two subjects' bodily responses at the defect locations, we find that subject A's bodily responses are generally smaller than those of subject B. In particular, subject A's bodily responses at the defect locations are lower than his/her responses in other locations, which could mean that the subject moves carefully in the defect location. On the other hand, subject B's bodily responses at the defect locations are much higher than at non-defective locations. Considering the differences between these two subjects, we see that while bodily responses can indicate defects, there is no specific response that acts as a guaranteed indicator since either a high or a low response can indicate defects. 

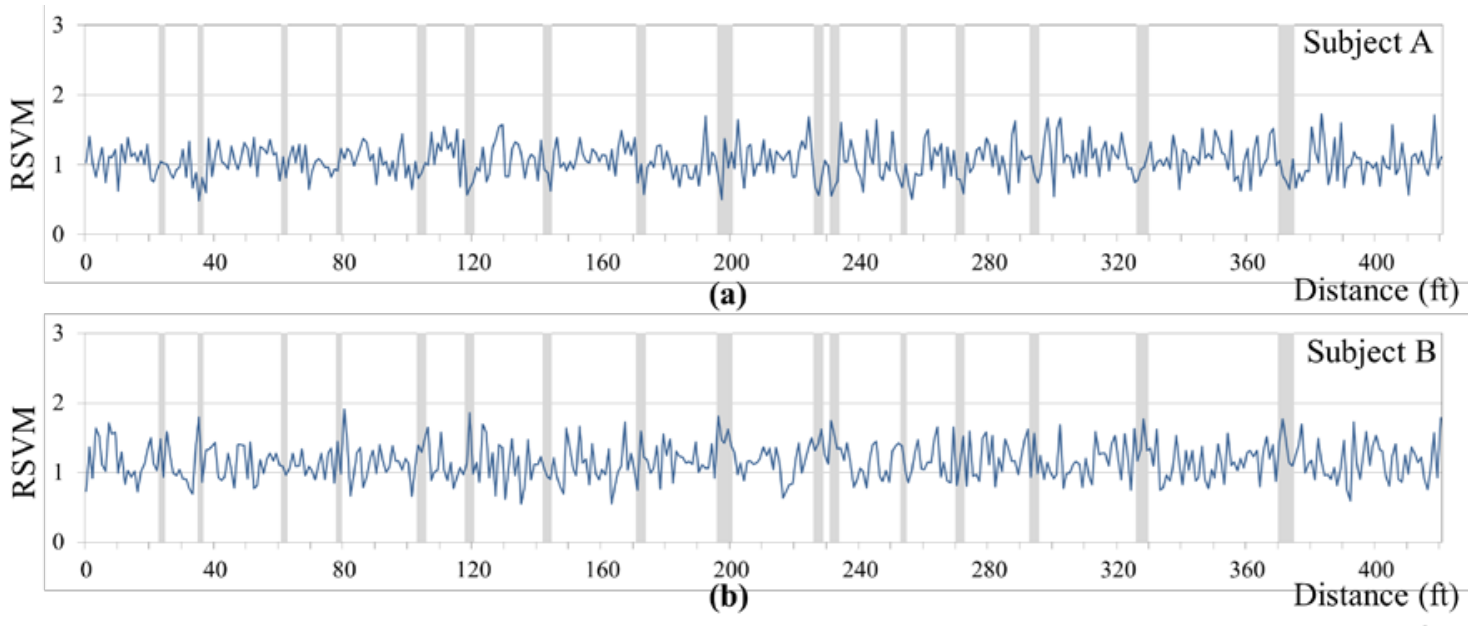

423

424

425

426

427

428

429

430

431

432

433

434

435

436

437

438

439

440

Figure 5. Example of Different Bodily Responses from Two Subjects

3

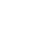

(1)

However, the response distribution obtained from collective sensing can provide another perspective for analyzing responses. Every pedestrian has different, individual traits such as their level of observation, their risk-taking tendencies, and their physical characteristics. The differences between subjects can explain why the collective sensing approach is required to detect a defect in sidewalk. As shown in Figure 5, two subjects' bodily responses differ as they walk along the sidewalk, but especially differ at the defect location. Subject A exhibits precautionary behaviors (e.g., he decreases his velocity before walking on defect) and avoids most defects (e.g., steps over defects). On the other hand, subject B's behavior showed no consideration of the defect's existence in the experiment as he did not adjust his velocity. One explanation is that he may not perceive the specific defect (defined by the governmental regulations) as being personally hazardous. As the number of subjects increases, the diversity of responses gradually increases. Collective sensing is a method that can capture both the diversity of responses and the normality of response distribution, which can indicate a defect's existence. 


\subsection{Detecting Defective Sidewalks}

As mentioned in the previous section, the key factor in detecting sidewalk defects is pedestrians' bodily responses, which are the result of the interaction between sidewalk surfaces and pedestrians. Specifically, this study found the interesting point that the distribution of bodily responses (normality) can be used to estimate the existence of sidewalk defects. However, the reason why the degree of normality differs by whether or not a defect exists has not yet been explained. This section will discuss the reason in terms of walking patterns. bodily responses. If there are no factors that disturb the maintenance of his or her walking pattern, the walking pattern is regular; i.e., under normal walking conditions, a pedestrian does not change his or her walking patterns frequently within a short time period [55]. The overlapped regular patterns collected from various pedestrians in a specific location may create a distribution of bodily responses with high normality. Because each individual has a different stride length, the foot location (the start and end points of a stride) in a specific location may be different. If the patterns are regular and repetitive, the walking pattern (represented as RSVM values in this study) tends to be similar to the average walking patterns. Because the RSVM values are calculated based on location (segment length)—not the cycle of gait - the calculated RSVM values are not always same, even if the walking pattern is exactly same. For example, if the pattern length is $3.5 \mathrm{ft}$ and the segment length is 1 $\mathrm{ft}$, the RSVM value can be distributed by each foot. These distributed RSVM values, collected in a non-defective location, are similar and have a normal distribution. Unlike in the non-defect situation, however, a defect can change the walking patterns of a pedestrian [56]. When a pedestrian encounters a defect on the route, he or she may determine where the next foot location should be. For instance, there may be several options available, such as 
increasing a stride length to step over the defect, decreasing a stride length to prepare to

467 bypass the defect, changing the route (moving away from the defect) to avoid the defect, or ignoring the defect and stepping on it. These pattern changes can cause irregular responses, which are represented as abnormal acceleration values. The irregular responses for responding to a defect cause the distribution of the collective responses within a specific location to be dispersed (low normality).

In addition to the cases mentioned above, there are other possibilities by which a defect can affect pedestrians' walking patterns even though there is no direct interaction (contact) between the pedestrian and defect. For example, pedestrians tend to walk in the middle of a sidewalk unless passing others [57]. Thus, we might assume that a defect located at the edge of the sidewalk would not affect pedestrians' behavior on a sidewalk with no one else around. However, humans often have a strong sense of personal space $[58,59]$. When a pedestrian expects that someone or something will intrude into this personal space, the pedestrian usually moves to avoid the intrusion if there is enough space to do [60]. This common avoidance behavior can be directly applied to this study. Some subjects may not want to allow a defect to intrude into their personal space. Consequently, bodily response changes may occur in order to maintain their personal space (moving a certain distance from a defect).

A second possibility is skipping a defect by happenstance. Each pedestrian has a walking pattern, including a walking pace. If each pace is three feet and the last point of contact between the foot and sidewalk is one foot behind the defect, the next footfall will naturally be located two feet in front of the defect. In this case, the data may not be able to indicate the existence of a defect, and would read very similarly to data observed at non-defect locations. Cases such as these, caused by individual differences, may provide a challenge to this study. Therefore, we need to address them through data aggregation and collective analysis. The data observed at a particular defect location may include various types of behaviors such as 
stepping, skipping, and avoiding the defect; these behaviors make it difficult for pedestrians to maintain their regular walking patterns. The abnormal behaviors caused by responding to this defect may disperse the distribution at this location. Consequently, reviewing collective bodily responses from all pedestrians can indicate the existence of a defective sidewalk.

\subsection{Effect of Pedestrians' Familiarity on Defective Sidewalk Detection}

Although there is promise in the idea that pedestrians' collective bodily responses can indicate the existence of defects, there is another factor that should be considered before applying the suggested method to practical use. According to various studies [61-63], familiarity with a place or a space affects pedestrian behaviors. Each sidewalk has a different user base, however. For example, a sidewalk near a tourist attraction (e.g., Times Square, which is traversed by more than 400,000 pedestrians per day) would have a relatively minimal number of pedestrians who are familiar with the sidewalk, but a large number of pedestrians who are unfamiliar with the sidewalk. On the other hand, a sidewalk in a suburb community is likely to have a higher percentage of pedestrians who are generally familiar with the sidewalk. To ascertain the effects of the familiarity of pedestrians with sidewalks, we perform a comparison between two groups by classified by familiarity level. Among the 17 subjects who participated in the experiment, nine subjects (the "familiar" group) are the residents of the nearby Nebraska hall and are familiar with the experiment sidewalk. The other eight subjects (the "unfamiliar" group) are unfamiliar with the sidewalk.

Figure 5 illustrates the average of the RSVM values of the two groups respectively. Comparing the two groups' average RSVMs, the unfamiliar group (see Figure 6-a) displayed higher peak points than did the familiar group (see Figure 6-b). In particular, the unfamiliar group presented much higher average RSVM values at $36 \mathrm{ft}, 232 \mathrm{ft}$, and $271 \mathrm{ft}$. The point biserial correlation coefficients of each group are 0.68 (unfamiliar group) and 0.44 (familiar 
group). Because familiarity can be understood as predictability (e.g., already having

517 knowledge of a defect's existence or location), subjects in the familiar group showed a lower RSVM value average. This result may indicate that responses collected from a group of subjects who are unfamiliar with the terrain in question could be much more suitable for detecting a defect on sidewalks than responses from subjects with familiarity.
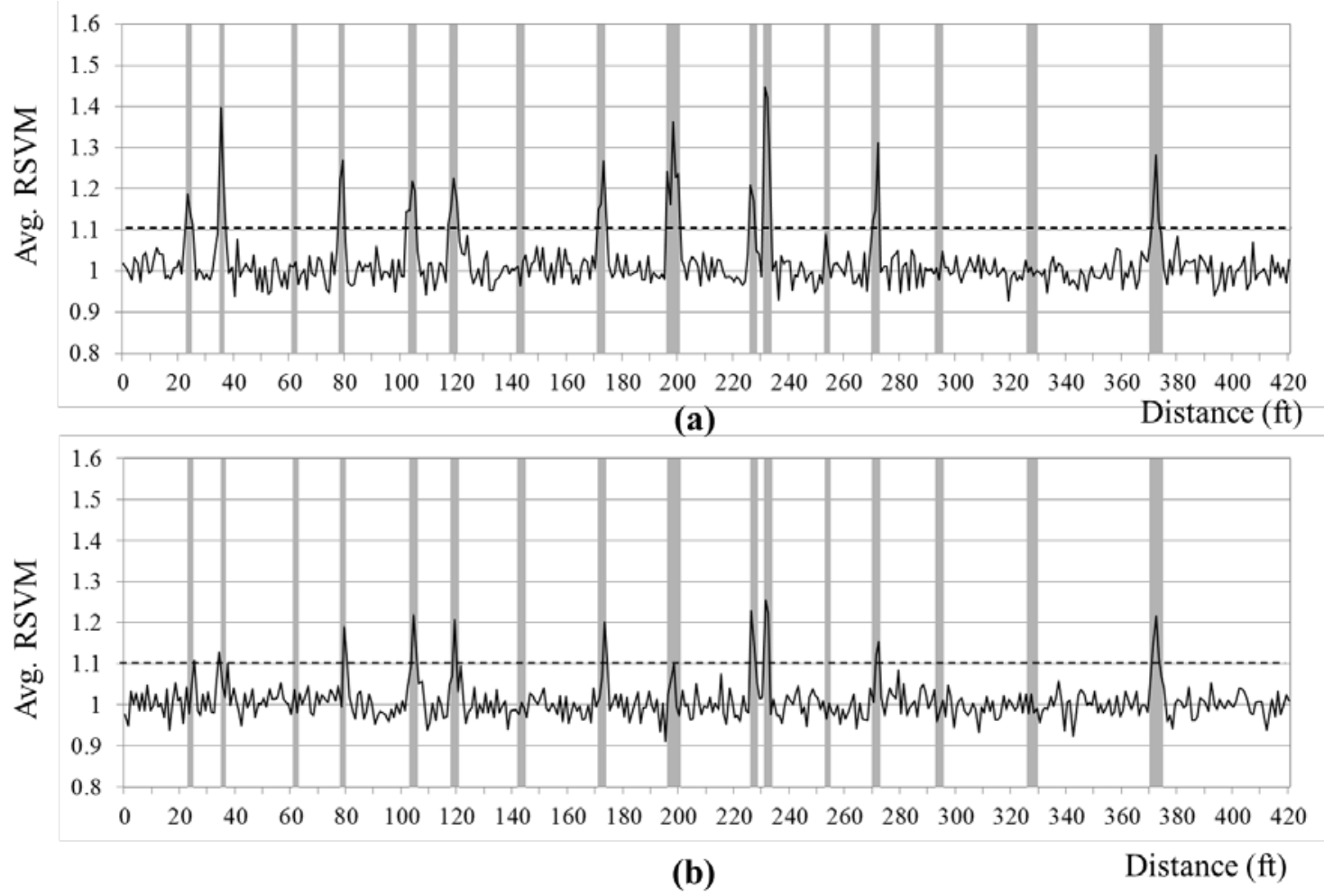

Figure 6. Calculation Results of the Average of RSVM Values: (a) Unfamiliar Group and

(b) Familiar Group

In a comparison of Shapiro-Wilk statistic $(W)$, the difference between the two groups is

527 less than the difference of the average of RSVMs (see Figure 7). Unlike the average of RSVMs, the Shapiro-Wilk statistics of the two groups on defects located from $79 \mathrm{ft}$ to $295 \mathrm{ft}$ have similar features. Although the comparison of the point biserial coefficients of the average of RSVMs between the two groups showed differences, the point biserial correlation 
531 coefficients of the two groups are very similar (unfamiliar group: -0.85; familiar group: -0.81).

532 The point biserial coefficients of both groups are significantly correlated with defect locations.

533 This result indicates that the normality of pedestrians' bodily responses can provide 534 information related to the existence of a defect. Even if pedestrians are familiar with a 535 sidewalk, their responses are dispersed at a defect location. This response dispersion, which 536 can be observed in both groups, does not make a noticeable difference in the collective 537 response patterns of either group.

538
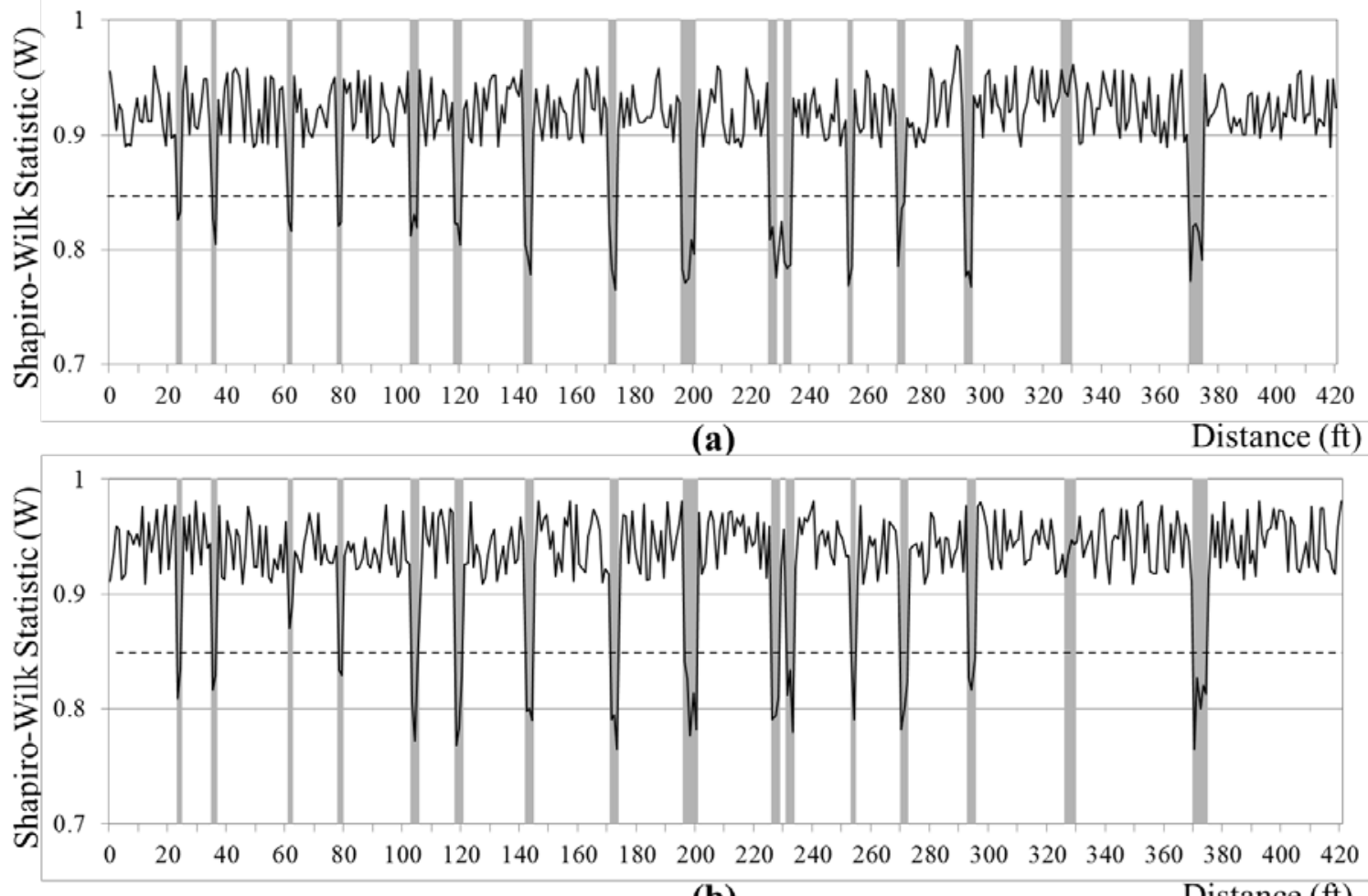

539

(b)

Distance (ft)

Figure 7. Calculation Results of the Shapiro-Wilk Statistic: (a) the Average of RSVM

Values; and (b) the Shapiro-Wilk Statistic $(W)$

5.4 The Possibility of Using People-Centric Sensing to Detect Defects

Current defective sidewalk detection is usually conducted by trained inspectors from 
545 governmental agencies. Because of staffing and budget limitations, the intervals between 546 inspections are generally long. For example, in Dubuque (Iowa) and Omaha (Nebraska), 547 sidewalk inspections only occur once a year. If a defect forms in a location between 548 scheduled checks, the defect is not registered in the management process. In contrast to this 549 practice, the suggested approach in this paper inspects the condition of sidewalks based on 550 participatory pedestrians' bodily responses. Whenever a participating pedestrian walks along 551 a sidewalk, the sidewalk is continuously estimated without an overlong inspection interval. 552 Compared to current inspector-led practices, this approach will reduce the time needed to detect a defect.

Moreover, the suggested approach can provide another advantage related to regulation development. According to the Occupational Safety and Health Administration, the duration of the regulation-formation process is 52 to 138 months [64]. Considering the significant effort needed to develop regulations, a people-centric sensory approach could be regarded as a part of a solution that is user-oriented and time-effective. Focusing on the detection of defective sidewalks, this people-centric sensory approach can reduce the need for regulation development. By collecting and analyzing pedestrians' bodily responses, we can automatically detect a defect that causes abnormal responses. Consequently, a sidewalk condition that actually functions as a defect-whether it meets the current criteria for a regulated defect or not—can be found without additional regulation development.

Despite these advantages, however, there are several challenges that must be overcome for a people-centric sensory approach to be feasible, including ensuring consistent sensor calibration [65], recruiting and sampling participants [66], and protecting the privacy of participants [26]. Although research related to people-centric sensing is still in its infancy, it is expected that the suggested challenges will be addressed in the near future [67]. 


\subsection{Limitations and Future Research}

This study focused on investigating the feasibility of utilizing a people-centric sensing technique for detecting sidewalk defects. Although the results supported the feasibility of the approach, there may be several hurdles such as diverse pedestrians and their behaviors as well as complex environment in the way of applying the proposed approach to the real world. Moreover, pedestrians' walking behaviors and the conditions of sidewalks are too complicated to have been fully incorporated into the experiment we conducted. Despite these acknowledged limitations, however, the authors' primary task in this study was to investigate the feasibility of the proposed approach, since that feasibility had not yet been reviewed. Although the selection of scale and the fixed carriage type may limit us from generalizing our research findings to other situations such as pedestrian crowds, uneven or sloped sidewalks, or sidewalks with more diverse components, we needed to control all these other independent variables mentioned above in order to conduct a baseline study on the feasibility of responsebased detection in any setting.

However, future study requires further incorporation of pedestrians' various behaviors and diverse elements on a sidewalk. For example, in this study, each subject (pedestrian) remained on the experiment path alone. In future studies, the interaction between pedestrians should be considered as well as that between a single pedestrian and the existence of a defect. On a crowded sidewalk, pedestrians' behaviors may differ from those displayed under the experiment conditions. Moreover, diverse external physical conditions such as the existence of trees, the velocity of vehicles passing near the sidewalk, sidewalk width, and surrounding built environment $[68,69]$ should be considered in the future study. An additional line of inquiry could involve disabled persons or the elderly, who may be more sensitive to the existence of a defect than younger or more able-bodied people. The different physical abilities of pedestrians should be investigated. In future studies, these diverse situations will 
595 be further investigated. Besides situations related to pedestrians, a deeper look at the 596 applicability of the proposed approach is required. In this study, the collected data are stored 597 in a smart phone. This means that the collected data would need to be transferred to a local 598 server manually. This process may be a time-consuming task, thus it should be handled. 599 Fortunately, the recent development of techniques like crowd-sourced sensing networks can 600 solve this problem. This study utilized a smartphone, which included data transfer methods in a real-time manner. As the next stage of this research, a crowd-sourced system will be developed to enhance the applicability of this approach to real-world applications. Once the system is developed, diverse external physical conditions and pedestrians' behaviors will be further analyzed to apply the system to a large scaled city district.

\section{CONCLUSIONS}

Sidewalk quality is a crucial factor impacting the built environment. However, current defective-sidewalk regulations and detection procedures are limited due both to the fact that they do not incorporate interaction in human-physical systems, and to their labor-intensive methodologies. This study investigates the feasibility of harnessing pedestrians' bodily responses to sidewalks as a means of detecting defects in sidewalks. To test the feasibility of this idea, an experiment with 17 subjects was conducted, and their bodily responses were collected using IMU sensors and GPS devices installed in smartphones. The collected pedestrians' bodily responses were analyzed in the concept of average and $W$ statistic at a certain location. The results demonstrate that the normality of responses-represented as the $W$ statistic — at a certain location is highly correlated with a defect's existence. correlated with the abnormality observed in the distribution of collective pedestrians' bodily 
location is irregular in comparison to the distribution of responses to a non-defective portion of sidewalk. Moreover, this study demonstrates the feasibility of participatory sensing based on smartphone use, which can let users easily participate in the process of sidewalk evaluation. If pedestrians' bodily responses are collected, a particular location can be evaluated based on the suggested method. The suggested method can thus be used to detect defects in sidewalks and will also help establish a proactive approach to managing the quality of sidewalks.

\section{Acknowledgement}

This study was partially supported by the National Science Foundation (\#1538029). Any opinions, findings, conclusions, or recommendations expressed in this article are those of the authors and do not necessarily reflect the views of the National Science Foundation.

\section{References}

[1] R.C. Brownson, C.M. Hoehner, K. Day, A. Forsyth, J.F. Sallis, Measuring the built environment for physical activity: state of the science, Am. J. Prev. Med. 36 (2009) S99-S123.

[2] P.S. Dunston, C.E. Williamson, Incorporating maintainability in constructability review process, J. Manag. Eng. 15 (1999) 56-60.

[3] H. Ge, S. Asgarpoor, Reliability and maintainability improvement of substations with aging infrastructure, Power Deliv. IEEE Trans. On. 27 (2012) 1868-1876.

[4] J.P. Hao, Y.L. Yu, Q. Xue, A maintainability analysis visualization system and its development under the AutoCAD environment, J. Mater. Process. Technol. 129 (2002) 277-282.

[5] A. Frackelton, Pedestrian transportation project prioritization incorporating appcollected sidewalk data, (2013). https://smartech.gatech.edu/handle/1853/50334 (accessed December 15, 2015).

[6] B. Landis, V. Vattikuti, R. Ottenberg, D. McLeod, M. Guttenplan, Modeling the roadside walking environment: pedestrian level of service, Transp. Res. Rec. J. Transp. Res. Board. (2001) 82-88.

[7] NYC DOT - Sidewalk Inspection and Violations, (n.d.). http://www.nyc.gov/html/dot/html/infrastructure/sidewalk-inspection.shtml (accessed May 27, 2016).

[8] TRN-1.11 - Sidewalk Maintenance Program Policy and Operating Guidelines | Streets \& Sidewalks | The City of Portland, Oregon, (n.d.). 
http://www.portlandoregon.gov/citycode/?c=27478\&a=98483 (accessed May 27, 2016).

[9] Scott M. Stringer, Claims Report - New York City Comptroller, (2015). http://comptroller.nyc.gov/wpcontent/uploads/documents/Claims_Report_FY13_and_FY14.pdf (accessed September 3, 2015).

[10] I. Altman, J.F. Wohlwill, Human behavior and environment: Advances in theory and $\begin{array}{llll}\text { research, Springer } \quad \text { Science } \& \text { Business } & 2012 .\end{array}$ https://books.google.co.kr/books?hl=en\&lr=\&id=BIHgBwAAQBAJ\&oi=fnd\&pg=PA2 $\& \mathrm{dq}=\% 22$ physical+environment $\% 22+\% 22$ human+behavior $\% 22 \&$ ots $=$ JdDAuPMS0c \&s ig=GzHJsY1PyJajOGLXOfRJlBv2AJU (accessed November 13, 2015).

[11] R. Gifford, Environmental psychology: Principles and practice, Optimal books Colville, WA, 2007. http://www.ise.virginia.edu/syllabi/F10/BARNES_SEMS_2500.pdf (accessed November 13, 2015).

[12] H.A. Simon, Invariants of human behavior, Annu. Rev. Psychol. 41 (1990) 1-20.

[13] D. Stokols, I. ALTMAN, Environmental psychology, Percept. Cogn. Image City. 12 (1987) 23.

[14] L.-K. Lin, C.-Y. Jian, Maintenance Algorithm and Management System of Sidewalk Facility, J. Mar. Sci. Technol. 18 (2010) 723-730.

[15] P.S. Kian, H. Feriadi, W. Sulistio, K.C. Seng, A case study on total building performance evaluation of an intelligent office building in Singapore, Civ. Eng. Dimens. 3 (2004) pp9.

[16] C.-H. Tseng, F. Hadipriono, J. Duane, P. Maughan, E.W. Whitlatch, Safety evaluation for campus parking garage performance using fuzzy logic, J. Perform. Constr. Facil. 18 (2004) 127-135.

[17] H.D. Cheng, X.J. Shi, C. Glazier, Real-time image thresholding based on sample space reduction and interpolation approach, J. Comput. Civ. Eng. 17 (2003) 264-272.

[18] C.M. Robinson, Among the Improvement Clubs, Munic. J. Eng. 112 (1902).

[19] H. Lu, W. Pan, N.D. Lane, T. Choudhury, A.T. Campbell, SoundSense: scalable sound sensing for people-centric applications on mobile phones, in: Proc. 7th Int. Conf. Mob. Syst. Appl. Serv., ACM, 2009: pp. 165-178. http://dl.acm.org/citation.cfm?id=1555834 (accessed August 27, 2015).

[20] A.T. Campbell, S.B. Eisenman, N.D. Lane, E. Miluzzo, R. Peterson, H. Lu, X. Zheng, M. Musolesi, K. Fodor, G.-S. Ahn, others, The rise of people-centric sensing, Internet Comput. IEEE. 12 (2008) 12-21.

[21] M. Wirz, D. Roggen, G. Tröster, User acceptance study of a mobile system for assistance during emergency situations at large-scale events, in: Hum.-Centric Comput. HumanCom 2010 3rd Int. Conf. On, IEEE, 2010: pp. 1-6. http://ieeexplore.ieee.org/xpls/abs_all.jsp?arnumber=5563347 (accessed August 27, 2015).

[22] E. Wahlgren, Pocket Protector, J. Life Sci. Febr. 13 (2008) 2008.

[23] L. Yang, W. Li, Y. Ge, X. Fu, R. Gravina, G. Fortino, People-Centric Service for mHealth of Wheelchair Users in Smart Cities, in: Internet Things Based Smart Objects, Springer, 2014: pp. 163-179. http://link.springer.com/chapter/10.1007/978-3-31900491-4_9 (accessed September 2, 2015).

[24] N.D. Lane, M. Lin, M. Mohammod, X. Yang, H. Lu, G. Cardone, S. Ali, A. Doryab, E. Berke, A.T. Campbell, others, Bewell: Sensing sleep, physical activities and social interactions to promote wellbeing, Mob. Netw. Appl. 19 (2014) 345-359.

[25] S. Sigg, X. Fu, Social opportunistic sensing and social centric networking: enabling technology for smart cities, in: Proc. 2014 ACM Int. Workshop Wirel. Mob. Technol. 
Smart Cities, ACM, 2014: pp. 83-90. http://dl.acm.org/citation.cfm?id=2633674 (accessed September 2, 2015).

[26] A.T. Campbell, S.B. Eisenman, N.D. Lane, E. Miluzzo, R.A. Peterson, People-centric urban sensing, in: Proc. 2nd Annu. Int. Workshop Wirel. Internet, ACM, 2006: p. 18. http://dl.acm.org/citation.cfm?id=1234179 (accessed July 1, 2015).

[27] A. Mednis, G. Strazdins, R. Zviedris, G. Kanonirs, L. Selavo, Real time pothole detection using android smartphones with accelerometers, in: Distrib. Comput. Sens. Syst. Workshop DCOSS 2011 Int. Conf. On, IEEE, 2011: pp. 1-6. http://ieeexplore.ieee.org/xpls/abs_all.jsp?arnumber=5982206 (accessed September 21, 2015).

[28] S. Joo, C. Oh, A novel method to monitor bicycling environments, Transp. Res. Part Policy Pract. 54 (2013) 1-13.

[29] Q. Mourcou, A. Fleury, P. Dupuy, B. Diot, C. Franco, N. Vuillerme, Wegoto: A Smartphone-based approach to assess and improve accessibility for wheelchair users, in: 2013 35th Annu. Int. Conf. IEEE Eng. Med. Biol. Soc. EMBC, 2013: pp. 1194-1197. doi:10.1109/EMBC.2013.6609720.

[30] A. Frackelton, A. Grossman, E. Palinginis, F. Castrillon, V. Elango, R. Guensler, Measuring walkability: Development of an automated sidewalk quality assessment tool, Suburb. Sustain. 1 (2013) 4.

[31] J. Eriksson, L. Girod, B. Hull, R. Newton, S. Madden, H. Balakrishnan, The pothole patrol: using a mobile sensor network for road surface monitoring, in: Proc. 6th Int. Conf. Mob. Syst. Appl. Serv., ACM, 2008: pp. 29-39. http://dl.acm.org/citation.cfm?id=1378605 (accessed June 26, 2015).

[32] T. Kim, S.-K. Ryu, Review and analysis of pothole detection methods, J. Emerg. Trends Comput. Inf. Sci. 5 (2014) 603-608.

[33] C. Koch, I. Brilakis, Improving pothole recognition through vision tracking for automated pavement assessment, Adv. Eng. Inform. Press Httpdx Doi Org101016j Aci. 2 https://www.inf.bi.rub.de/intern/aigaion/documents/ImprovingPotholeRecognition.pdfa479b828088237153a37b5f16ac7f41f.pdf (accessed July 25, 2016).

[34] T.-K. Lim, S.-M. Park, H.-C. Lee, D.-E. Lee, Artificial Neural Network-Based Slip-Trip Classifier Using Smart Sensor for Construction Workplace, J. Constr. Eng. Manag. 142 (2015) 4015065.

[35] S. Han, S. Lee, F. Peña-Mora, Vision-based detection of unsafe actions of a construction worker: Case study of ladder climbing, J. Comput. Civ. Eng. 27 (2012) 635-644.

[36] S. Han, S. Lee, A vision-based motion capture and recognition framework for behaviorbased safety management, Autom. Constr. 35 (2013) 131-141.

[37] S.J. Ray, J. Teizer, Real-time construction worker posture analysis for ergonomics training, Adv. Eng. Inform. 26 (2012) 439-455.

[38] H. akan Sporrong, L. Sandsjö, R. Kadefors, P. Herberts, Assessment of workload and arm position during different work sequences: a study with portable devices on construction workers, Appl. Ergon. 30 (1999) 495-503.

[39] U.C. Gatti, S. Schneider, G.C. Migliaccio, Physiological condition monitoring of construction workers, Autom. Constr. 44 (2014) 227-233.

[40] H. Jebelli, C.R. Ahn, T.L. Stentz, Comprehensive Fall-Risk Assessment of Construction Workers Using Inertial Measurement Units: Validation of the Gait-Stability Metric to Assess the Fall Risk of Iron Workers, J. Comput. Civ. Eng. (2015) 4015034.

[41] S. Rietdyk, C.K. Rhea, The effect of the visual characteristics of obstacles on risk of tripping and gait parameters during locomotion, Ophthalmic Physiol. Opt. 31 (2011) 
302-310.

[42] S.A. England, K.P. Granata, The influence of gait speed on local dynamic stability of walking, Gait Posture. 25 (2007) 172-178.

[43] J.M. Hausdorff, Gait dynamics, fractals and falls: finding meaning in the stride-to-stride fluctuations of human walking, Hum. Mov. Sci. 26 (2007) 555-589.

[44] P. Li, R. Meziane, M.J.-D. Otis, H. Ezzaidi, P. Cardou, A Smart Safety Helmet using IMU and EEG sensors for worker fatigue detection, in: Robot. Sens. Environ. ROSE 2014 IEEE Int. Symp. On, IEEE, 2014: pp. 55-60. http://ieeexplore.ieee.org/xpls/abs_all.jsp?arnumber=6952983 (accessed April 20, 2015).

[45] C.-C. Lan, Y.-H. Hsueh, R.-Y. Hu, Real-time fall detecting system using a tri-axial accelerometer for home care, in: Biomed. Eng. Biotechnol. ICBEB 2012 Int. Conf. On, IEEE, 2012: pp. 1077-1080. http://ieeexplore.ieee.org/xpls/abs_all.jsp?arnumber=6245314 (accessed July 1, 2015).

[46] Y. CAO, W. CAI, Y. Cheng, Body Posture Detection Technique Based on MEMS Acceleration Sensor [J], Nanotechnol. Precis. Eng. 8 (2010) 37-41.

[47] A. Weiss, I. Shimkin, N. Giladi, J.M. Hausdorff, Automated detection of near falls: algorithm development and preliminary results, BMC Res. Notes. 3 (2010) 62.

[48] S.E. Anderson, G.E. Dallal, A. Must, Relative weight and race influence average age at menarche: results from two nationally representative surveys of US girls studied 25 years apart, Pediatrics. 111 (2003) 844-850.

[49] M.P. Riggs, J.M. Sheppard, The relative importance of strength and power qualities to vertical jump height of elite beach volleyball players during the counter-movement and squat jump, (2009). http://rua.ua.es/dspace/handle/10045/11729 (accessed November 16, 2015).

[50] W.J. Taylor, Average Length and Radius of Normal Paraffln Hydrocarbon Molecules, J. Chem. Phys. 16 (1948) 257-267.

[51] S.S. Shapiro, M.B. Wilk, An analysis of variance test for normality (complete samples), Biometrika. (1965) 591-611.

[52] P. Bobko, Correlation and regression: Applications for industrial organizational psychology and management, Sage Publications, 2001. https://books.google.co.kr/books?hl=en\&lr=\&id=x8RyAwAAQBAJ\&oi=fnd\&pg=PP1\& $\mathrm{dq}=$ Correlation+and+Regression:+Applications+for+Industrial+Organizational+Psychol ogy+and+Management\&ots=fWW2ygGCdn\&sig=q4Z1Z8Zyzzxw8T4FSFFlq60bkI8 (accessed December 11, 2015).

[53] J.W. Holley, K.-E. Berhagen, A Note on the Use of the Point Biserial Correlation Coefficient, Lund University, 1969.

[54] S. Sharma, Applied multivariate techniques, John Wiley \& Sons, Inc., 1995. http://dl.acm.org/citation.cfm?id=225519 (accessed March 28, 2016).

[55] J.-S. Wang, C.-W. Lin, Y.-T.C. Yang, Y.-J. Ho, Walking pattern classification and walking distance estimation algorithms using gait phase information, IEEE Trans. Biomed. Eng. 59 (2012) 2884-2892.

[56] H.B. Menz, S.R. Lord, R.C. Fitzpatrick, Acceleration patterns of the head and pelvis when walking on level and irregular surfaces, Gait Posture. 18 (2003) 35-46.

[57] W. Daamen, S. Hoogendoorn, Controlled experiments to derive walking behaviour, Eur. J. Transp. Infrastruct. Res. EJTIR 3 1. (2003). http://repository.tudelft.nl/assets/uuid:d6e2f68e-ae78-4529-8ccb5e63b927f56c/2003_01_03controlled.pdf (accessed July 28, 2016).

[58] I. Altman, The Environment and Social Behavior: Privacy, Personal Space, Territory, and Crowding., (1975). http://eric.ed.gov/?id=ED131515 (accessed July 28, 2016). 
[59] E. Walster, Assignment of responsibility for an accident., J. Pers. Soc. Psychol. 3 (1966) 73.

[60] M. Gérin-Lajoie, C.L. Richards, B.J. McFadyen, The negotiation of stationary and moving obstructions during walking: anticipatory locomotor adaptations and preservation of personal space, Mot. CONTROL-CHAMPAIGN-. 9 (2005) 242.

[61] M. Jaśkiewicz, T. Besta, Is easy access related to better life? Walkability and overlapping of personal and communal identity as predictors of quality of life, Appl. Res. Qual. Life. 9 (2014) 505-516.

[62] V. Mehta, Walkable streets: pedestrian behavior, perceptions and attitudes, J. Urban. 1 (2008) 217-245.

[63] M. Sugovic, J.K. Witt, An older view on distance perception: older adults perceive walkable extents as farther, Exp. Brain Res. 226 (2013) 383-391.

[64] OSHA, The OSHA Rulemaking Process, (2012). https://www.osha.gov/OSHA_FlowChart.pdf.

[65] J. Shi, R. Zhang, Y. Liu, Y. Zhang, Prisense: privacy-preserving data aggregation in people-centric urban sensing systems, in: INFOCOM 2010 Proc. IEEE, IEEE, 2010: pp. 1-9. http://ieeexplore.ieee.org/xpls/abs_all.jsp?arnumber=5462147 (accessed September 2, 2015).

[66] N.D. Lane, S.B. Eisenman, M. Musolesi, E. Miluzzo, A.T. Campbell, Urban sensing systems: opportunistic or participatory?, in: Proc. 9th Workshop Mob. Comput. Syst. Appl., ACM, 2008: pp. 11-16. http://dl.acm.org/citation.cfm?id=1411763 (accessed March 29, 2016).

[67] W. Moreira, P. Mendes, Pervasive data sharing as an enabler for mobile citizen sensing systems, Commun. Mag. IEEE. 53 (2015) 164-170.

[68] R. Ewing, S. Handy, Measuring the unmeasurable: urban design qualities related to walkability, J. Urban Des. 14 (2009) 65-84.

[69] R. Ewing, S. Handy, R.C. Brownson, O. Clemente, E. Winston, Identifying and measuring urban design qualities related to walkability, J. Phys. Act. Health. 3 (2006) S223. 